\title{
Another Antimagic Decomposition of Generalized Peterzen Graph
}

\author{
Nur Inayah*, M. Irvan Septiar Musti, and Soffi Nur Masyithoh \\ Department of Mathematics, UIN Syarif Hidayatullah Jakarta \\ Jln. Ir. H. Juanda no.95-Ciputat 15412, Tangerang Selatan, Indonesia \\ Email:*nur.inayah@uinjkt.ac.id, \{irvanseptiar, soffilee0113\}@gmail.com
}

\begin{abstract}
A decomposition of a graph $P$ into a family $\mathbb{Q}$ consisting of isomorphic copies of a graph $Q$ is $(\mathfrak{a}, b)$ $Q$-antimagic if there is a bijection $\varphi: V(P) \cup E(P) \rightarrow\left\{1,2,3,4 \ldots, v_{P}+e_{P}\right\}$ such that for all subgraphs $Q^{\prime}$ isomorphic to $Q$, the $Q$-weights

$$
\varphi\left(Q^{\prime}\right)=\sum_{v \in V\left(Q^{\prime}\right)} \varphi(v)+\sum_{e \in E\left(Q^{\prime}\right)} \varphi(e)
$$

constitute an arithmetic progression $\mathfrak{a}, \mathfrak{a}+b, \mathfrak{a}+2 b, \ldots, \mathfrak{a}+(r-1) b$ where $\mathfrak{a}$ and $b$ are positive integers and $r$ is the number of subgraphs of $P$ isomorphic to $Q$. In this article we prove the existence of a $(\mathfrak{a}, b)-P_{4}$-antimagic decomposition of a generalized Peterzen graph $\operatorname{GPz}(n, 3)$ for several values of $b$.
\end{abstract}

Keywords: covering; decomposition; antimagic; generalized Peterzen.

\begin{abstract}
Abstrak
Suatu dekomposisi dari suatu graf $P$ ke dalam suatu famili $\mathbb{Q}$ yang terdiri dari salinan isomorfik dari graf $Q$ dikatakan $(\mathfrak{a}, b)$-Q-antiajaib jika terdapat pemetaaan bijektif $\varphi: V(P) \cup E(P) \rightarrow\left\{1,2,3,4 \ldots, v_{P}+e_{P}\right\}$ sedemikian sehingga semua subgraf $Q$ ' yang isomorfik. ke $Q$, dengan bobot- $Q$ sebagai berikut

$$
\varphi\left(Q^{\prime}\right)=\sum_{v \in V\left(Q^{\prime}\right)} \varphi(v)+\sum_{e \in E\left(Q^{\prime}\right)} \varphi(e)
$$

yang membentuk suatu barisan aritmatika yaitu $\mathfrak{a}, \mathfrak{a}+b, \mathfrak{a}+2 b, \ldots, \mathfrak{a}+(r-1) b$ dengan $\mathfrak{a}$ dan $b$ adalab bilangan bulat positif dan radalah banyaknya subgraf dari P yang isomorfik ke $Q$. Pada artikel ini, kami membuktikan eksistensi $(\mathfrak{a}, b)$ - $P_{4}$-antiajaib dekomposisi dari graf generalized Peterzen $\operatorname{GPz}(n, 3)$ untuk beberapa nilai $b$.

Kata kunci: selimut; dekomposisi; antiajaib; generalized Peterzen.
\end{abstract}

\section{INTRODUCTION}

All graphs are finite and simple graphs. The edge and vertex sets of a graph $P$ are denoted by $V(P)$ and $E(P)$, respectively, where $|V(P)|=v_{P}$ and $|E(P)|=e_{P}$. A graph labeling of a graph $P$ is a bijective function that carries a set of elements of $P$ onto a set of labels, usually, a set of positive integers. If the domain and co-domain of this function are $V(P) \cup E(P)$ and the set $\left\{1,2,3,4, \cdots, v_{P}+e_{P}\right\}$, respectively, then it is called a total labeling.

An edge-covering of $P$ is a family of subgraphs $\mathbb{Q}=\left\{Q_{1}, Q_{2}, Q_{3}, \ldots, Q_{k}\right\}$ such that each edge of $E(P)$ belongs to at least one of the subgraphs $Q_{i}, 1 \leq i \leq k$. Then it is said that $P$ admits an $\left(Q_{1}, Q_{2}, Q_{3}, \ldots, Q_{k}\right)$-(edge) covering. If every $Q_{i}$ is isomorphic to aiven graph $Q$, then $P$ admits an

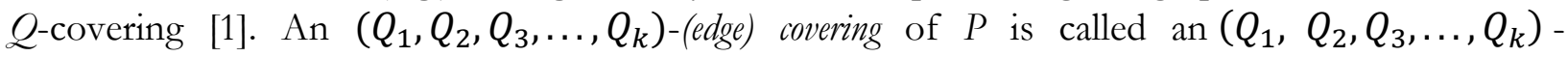

Submitted March $4^{\text {th }}, 2021$, Revised October $10^{\text {th }}, 2021$, Accepted for publication October $11^{\text {th }}, 2021$.

This is an open access article under CC-BY-SA license (https://creativecommons.org/licence/by-sa/4.0/) 
decomposition, if $E\left(Q_{i}\right) \cap E\left(Q_{j}\right)=\emptyset$ for $i \neq j$. If every $Q_{i}$ is isomorphic to a given graph $Q$, then $P$ admits an $Q$-decomposition.

Suppose $P$ admits an $Q$-decomposition and let $f: V(P) \cup E(P) \rightarrow\left\{1,2,3,4 \ldots, v_{P}+e_{P}\right\}$ be a total labeling. An $Q$-weight of a subgraph $Q$ of $P$ under a total labeling is the sum of all edge and vertex labels on $Q$. If every subgraph $Q \in \mathbb{Q}$ has the same $Q$-weights, then it is called an $Q$-magic decomposition of $P$. If all $Q \in \mathbb{Q}$ have distinct $Q$-weights, then it is called an $Q$-antimagic decomposition of $P$. In particular, if $Q$-weights of all $Q \in \mathbb{Q}$ are an arithmetic sequence with the first term $a$ and a common difference $b$ then it is called an $(a, b)$ - $H$-antimagic decomposition of $P$.

Inayah et al. [2] [3] introduced an $(\mathfrak{a}, b)$ - $Q$-antimagic total labeling of a graph $P$ admitting an $Q$ decomposition, denoted as an $(\mathfrak{a}, b)$-Q-antimagic decomposition as a bijective function $\phi: V(P) \cup E(P) \rightarrow\{1,2,3,4 \ldots,|V(P)|+|E(P)|\}$ such that for a subgraph $Q^{\prime}$ isomorphic to $Q$, the $Q_{\text {-weights }} \varphi\left(Q^{\prime}\right)=\sum_{v \in V\left(Q^{\prime}\right)} \varphi(v)+\sum_{e \in E\left(Q^{\prime}\right)} \varphi(e)$ constitute an arithmetic progression $\mathfrak{a}, \mathfrak{a}+b, \mathfrak{a}+2 b, \ldots, \mathfrak{a}+(r-1) b$ where $\mathfrak{a}$ and $b$ are positive integers and $r$ is the number of all subgraphs of $P$ isomorphic to $Q$. The recent results on this subject can be seen, as an example, in [4] and [5]. The complete results can be seen in a dynamic survey of graph labelings by Gallian [6].

In this article, we proved $(\mathfrak{a}, b)-P_{4}$-antimagic decompositions of generalized Peterzen graphs $\operatorname{GPz}(n, 3)$. We show that the graphs admit $(a, b)-P_{4}$-antimagic decompositions for several values of $b$.

\section{MAIN RESULTS}

In this section, we prove the existence of the $(a, b)-P_{4}$-antimagic decomposition of the generalized Peterzen graph $\operatorname{GPz}(n, 3)$ for $b \in\{1,2,3,4,5\}$. Watkins [7] defined the generalized Peterzen graph $\operatorname{GPz}(n, 3)$ as a graph having vertex set

and edge set

$$
V(G P z(n, 3))=\left\{v_{i}, u_{i}: 0 \leq i \leq n-1\right\}
$$

$$
\begin{gathered}
\text { Outer } \operatorname{Rim} E_{O}\left((G P z(n, k))=\left\{u_{i} u_{(i+1) \bmod n}\right\}_{i=0}^{n-1},\right. \\
\text { Inner } \operatorname{Rim} E_{I}\left((G P z(n, k))=\left\{v_{i} v_{(i+k) \bmod n}\right\}_{i=0}^{n-1},\right. \\
\text { Spoke } E_{S}(n, k)=\left\{u_{i} v_{i}\right\}_{i=0}^{n+1} .
\end{gathered}
$$

Let $\mathbb{Q}=\left\{P_{4}^{0}, P_{4}^{1}, \ldots, P_{4}^{n-1}\right\}$, where the edge and vertex sets of the subgraph $P_{4}^{i}$ defined as follows: For $i \in[0, n-1]$,

$$
\begin{gathered}
V\left(P_{4}^{i}\right)=\left\{v_{i}, v_{(i+3) \bmod n}, u_{i}, u_{(i+1) \bmod n}: 0 \leq i \leq n-1\right\}, \\
E\left(P_{4}^{i}\right)=\left\{v_{i} v_{(i+3) \bmod n}, u_{i} v_{i}, u_{i+1} u_{(i+1) \bmod n}: 0 \leq i \leq n-1\right\} .
\end{gathered}
$$

It is not difficult to see that $\mathbb{Q}=\left\{P_{4}^{0}, P_{4}^{1}, \ldots, P_{4}^{n-1}\right\}$ is a $P_{4}$-decomposition of $\operatorname{GPz}(n, 3)$. Figure 1 displays the generalized Peterzen Graph $\operatorname{GPz}(n, 3)$. 


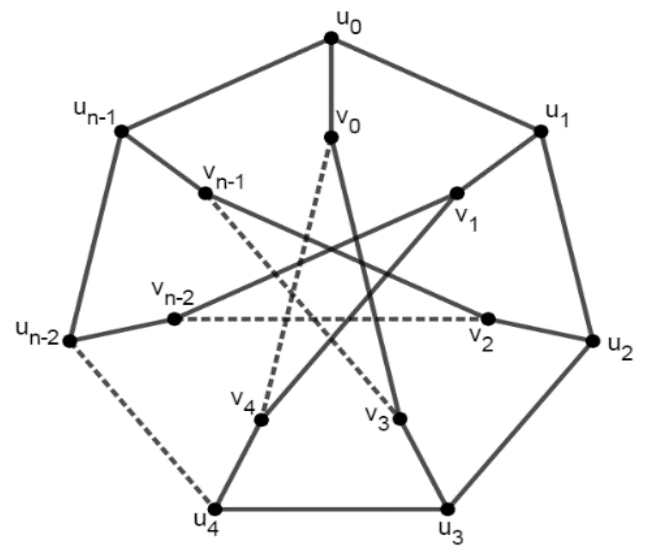

Figure 1. Generalized Peterzen Graph $\operatorname{GPz}(n, 3)$

Theorem 1. For any integer $n \geq 7$, the graph $\operatorname{GPz}(n, 3)$ has a $(20 n+4,1)$ - $P_{4}$-antimagic decomposition. Proof. Define a total labeling $\Psi_{q}$ on the edges and vertices of the graph $\operatorname{GPz}(n, 3)$ in the following way

$$
\begin{aligned}
& \Psi_{q}\left(v_{i} v_{(i+3) \bmod n}\right)= \begin{cases}i+5 & \text { for } i \in[0, n-5] \\
-n+i+5 & \text { for } i \in[n-4, n-1]\end{cases} \\
& \Psi_{q}\left(v_{i} u_{i}\right) \quad= \begin{cases}2 n & \text { for } i=0 \\
n+i & \text { for } i \in[1, n-1]\end{cases} \\
& \Psi_{q}\left(u_{i} u_{(i+1) \bmod n}\right)= \begin{cases}2 n+1 & \text { for } i=0 \\
3 n-i+1 & \text { for } i \in[1, n-1]\end{cases} \\
& \Psi_{q}\left(u_{i}\right) \quad= \begin{cases}4 n-i-3 & \text { for } i \in[0, n-5] \\
5 n-i-3 & \text { for } i \in[n-4, n-1]\end{cases} \\
& \Psi_{q}\left(v_{i}\right) \quad=4 n+i+1 \quad \text { for } i \in[0, n-1]
\end{aligned}
$$

It can be seen that the labeling $\psi_{q}$ is a bijective function from $E(G P z(n, 3)) \cup V(G P z(n, 3))$ to $\{1,2,3,4, \ldots, 3 n\}$ and $\psi_{q}(V(G P z(n, 3)))=\{1,2,3,4 \ldots, n+1\}$. Furthermore, the $P_{4}$-weight under the labeling $\psi_{q}$ are as follows.

$$
w\left(P_{4}^{i}\right)=\left\{\begin{array}{c}
\Psi_{q}\left(v_{(i+3)}\right)+\Psi_{q}\left(v_{i} v_{(i+3)}\right)+\Psi_{q}\left(v_{i}\right)+\Psi_{q}\left(v_{i} u_{i}\right)+\Psi_{q}\left(u_{i}\right) \\
+\Psi_{q}\left(u_{i} u_{(i+1)}\right)+\Psi_{q}\left(u_{(i+1)}\right), \text { for } i \in[0, n-4] \\
\Psi_{q}\left(v_{0}\right)+\Psi_{q}\left(v_{i} v_{0}\right)+\Psi_{q}\left(v_{i}\right)+\Psi_{q}\left(v_{i} u_{i}\right)+\Psi_{q}\left(u_{i}\right) \\
+\Psi_{q}\left(u_{i} u_{(i+1)}\right)+\Psi_{q}\left(u_{(i+1)}\right), \text { for } i=[n-3] \\
\Psi_{q}\left(v_{1}\right)+\Psi_{q}\left(v_{i} v_{1}\right)+\Psi_{q}\left(v_{i}\right)+\Psi_{q}\left(v_{i} u_{i}\right)+\Psi_{q}\left(u_{i}\right) \\
+f_{q}\left(u_{i} u_{(i+1)}\right)+f_{q}\left(u_{(i+1)}\right), \text { for } i=[n-2] \\
\Psi_{q}\left(v_{2}\right)+\Psi_{q}\left(v_{i} v_{2}\right)+\Psi_{q}\left(v_{i}\right)+\Psi_{q}\left(v_{i} u_{i}\right)+\Psi_{q}\left(u_{i}\right) \\
+\Psi_{q}\left(u_{i} u_{1}\right)+\Psi_{q}\left(u_{0}\right), \text { for } i=[n-1]
\end{array}\right.
$$

For $i \in[0, n-1]$, under labeling $\psi_{q}$, we find 


$$
\begin{aligned}
w\left(P_{4}^{i}\right)= & w\left(P_{4}^{i}\right)=\Psi_{q}\left(v_{(i+3)}\right)+\Psi_{q}\left(v_{i} v_{(i+3)}\right)+\Psi_{q}\left(v_{i}\right)+\Psi_{q}\left(v_{i} u_{i}\right)+\Psi_{q}\left(u_{i}\right)+\Psi_{q}\left(u_{i} u_{(i+1)}\right)+ \\
& \Psi_{q}\left(u_{(i+1)}\right) \\
= & (4 n+(i+3)+1)+(i+5)+(4 n+i+1)+(2 n)+(4 n-i-3)+(2 n+1)+ \\
= & (4 n-(i+1)-3) \\
= & 20 n+i+4
\end{aligned}
$$

Since $w\left(P_{4}^{i+1}\right)-w\left(P_{4}^{i}\right)=1$ and $w\left(P_{4}^{0}\right)=20 n+4$, the generalized Peterzen $\operatorname{GPz}(n, 3)$ admits a $(20 n+4,1)-P_{4}$-antimagic decomposition.
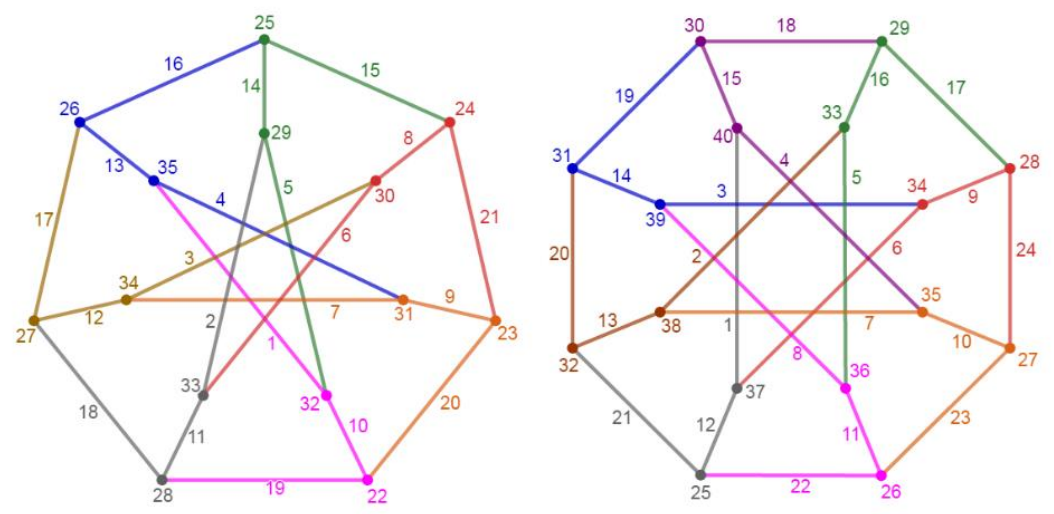

Figure 2. A $(144,1)-P_{4}$-Antimagic Decomposition of Generalized Peterzen Graph $G P z(7,3)($ left $)$, a $(164,1)-P_{4}-$ Antimagic Decomposition of Generalized Peterzen Graph $G P z(8,3)$ (right).

Theorem 2. For any integer $n \geq 7$, the graph $\operatorname{GPz}(n, 3)$ has a $(14 n+4,2)-P_{4}$-antimagic decomposition.

Proof. Define a total labeling $\Psi_{e}$ on the edges and vertices of the graph $\operatorname{GPz}(n, 3)$ in the following way

$$
\begin{array}{lll}
\Psi_{e}\left(v_{i} v_{(i+3) \bmod n}\right) & = & \begin{array}{ll}
4 n+i+1 & \text { for } i \in[0, n-1]
\end{array} \\
\Psi_{e}\left(v_{i} u_{i}\right) & =\begin{array}{ll}
4 n+i-2 & \text { for } i \in[0,2] \\
3 n+i-2 & \text { for } i \in[3, n-1]
\end{array} \\
\Psi_{e}\left(u_{i} u_{(i+1) \bmod n}\right) & = \begin{cases}3 n-2 i-2 & \text { for } i \in[0, n-2] \\
5 n-2 i-2 & \text { for } i=[n-1]\end{cases} \\
\Psi_{e}\left(u_{i}\right) & =n+2 i+1 & \text { for } i \in[0, n-1] \\
\Psi_{e}\left(v_{i}\right) & = \begin{cases}-i+3 & \text { for } i \in[0,2] \\
n-i+3 & \text { for } i \in[3, n-1]\end{cases}
\end{array}
$$

It can be seen that the labeling $\psi_{e}$ is a bijective function from $E(G P z(n, 3)) \cup V(G P z(n, 3))$ to $\{1,2,3,4, \ldots, 3 n\}$ and $\psi_{e}(V(G P z(n, 3)))=\{1,2,3,4, \ldots, n+1\}$. Furthermore, the $P_{4}$-weight under the labeling $\psi_{e}$ are as follows 


$$
w\left(P_{4}^{i}\right)=\left\{\begin{array}{c}
\Psi_{e}\left(v_{(i+3)}\right)+\Psi_{e}\left(v_{i} v_{(i+3)}\right)+\Psi_{e}\left(v_{i}\right)+\Psi_{e}\left(v_{i} u_{i}\right)+\Psi_{e}\left(u_{i}\right) \\
+\Psi_{e}\left(u_{i} u_{(i+1)}\right)+\Psi_{e}\left(u_{(i+1)}\right), \text { for } i \in[0, n-4] \\
\Psi_{e}\left(v_{0}\right)+\Psi_{e}\left(v_{i} v_{0}\right)+\Psi_{e}\left(v_{i}\right)+\Psi_{e}\left(v_{i} u_{i}\right)+\Psi_{e}\left(u_{i}\right) \\
+\Psi_{e}\left(u_{i} u_{(i+1)}\right)+\Psi_{e}\left(u_{(i+1)}\right), \text { for } i=[n-3] \\
\Psi_{e}\left(v_{1}\right)+\Psi_{e}\left(v_{i} v_{1}\right)+\Psi_{e}\left(v_{i}\right)+\Psi_{e}\left(v_{i} u_{i}\right)+\Psi_{e}\left(u_{i}\right) \\
+\Psi_{e}\left(u_{i} u_{(i+1)}\right)+\Psi_{e}\left(u_{(i+1)}\right), \text { for } i=[n-2] \\
\Psi_{e}\left(v_{2}\right)+\Psi_{e}\left(v_{i} v_{2}\right)+\Psi_{e}\left(v_{i}\right)+\Psi_{e}\left(v_{i} u_{i}\right)+\Psi_{e}\left(u_{i}\right) \\
+\Psi_{e}\left(u_{i} u_{1}\right)+\Psi_{e}\left(u_{0}\right), \text { for } i=[n-1]
\end{array}\right.
$$

For $i \in[0, n-1]$, under labeling $\psi_{e}$, we find

$$
\begin{aligned}
w\left(P_{4}^{i}\right)= & \Psi_{e}\left(v_{(i+3)}\right)+\Psi_{e}\left(v_{i} v_{(i+3)}\right)+\Psi_{e}\left(v_{i}\right)+\Psi_{e}\left(v_{i} u_{i}\right)+\Psi_{e}\left(u_{i}\right)+\Psi_{e}\left(u_{i} u_{(i+1)}\right)+\Psi_{e}\left(u_{(i+1)}\right) \\
= & (n-(i+3)+3)+(4 n+i+1)+(-i+3)+(4 n+i-2)+(n+2 i+1)+(3 n-2 i- \\
& 2)+(n+2(i+1)+1) \\
= & 14 n+2 i+4
\end{aligned}
$$

Since $w\left(P_{4}^{i+1}\right)-w\left(P_{4}^{i}\right)=2$ and $w\left(P_{4}^{0}\right)=14 n+4$, the generalized Peterzen $\operatorname{GPz}(n, 3)$ admits a $(14 n+4,2)-P_{4}$-antimagic decomposition.

Theorem 3. For any integer $n \geq 7$, the graph $\operatorname{GPz}(n, 3)$ has a $(19 n+5,3)$ - $P_{4}$-antimagic decomposition.

Proof. Define a total labeling $\Psi_{r}$ on the edges and vertices of the graph $\operatorname{GPz}(n, 3)$ in the following way

$$
\begin{aligned}
& \Psi_{r}\left(v_{i} v_{(i+3) \bmod n}\right)=\quad i+1 \quad \text { for } i \in[0, n-1] \\
& \Psi_{r}\left(v_{i} u_{i}\right)= \begin{cases}2 n+i-1 & \text { for } i \in[0,1] \\
n+i-1 & \text { for } i \in[2, n-1]\end{cases} \\
& \Psi_{r}\left(u_{i} u_{(i+1) \bmod n}\right)=2 n+i+1 \quad \text { for } i \in[0, n-1] \\
& \Psi_{r}\left(u_{i}\right) \quad= \begin{cases}3 n-i+3 & \text { for } i \in[0,2] \\
4 n-i+3 & \text { for } i \in[3, n-1]\end{cases} \\
& \Psi_{r}\left(v_{i}\right) \quad= \begin{cases}5 n+i-2 & \text { for } i \in[0,2] \\
4 n+i-2 & \text { for } i \in[3, n-1]\end{cases}
\end{aligned}
$$

It can be seen that the labeling $\psi_{r}$ is a bijective function from $E(G P z(n, 3)) \cup V(G P z(n, 3))$ to $\{1,2,3,4, \ldots, 3 n\}$ and $\psi_{r}(V(G P z(n, 3)))=\{1,2,3,4, \ldots, n+1\}$. Furthermore, the $P_{4}$-weight under the labeling $\psi_{r}$ are as follows 


$$
w\left(P_{4}^{i}\right)=\left\{\begin{array}{c}
\Psi_{r}\left(v_{(i+3)}\right)+\Psi_{r}\left(v_{i} v_{(i+3)}\right)+\Psi_{r}\left(v_{i}\right)+\Psi_{r}\left(v_{i} u_{i}\right)+\Psi_{r}\left(u_{i}\right) \\
+\Psi_{r}\left(u_{i} u_{(i+1)}\right)+\Psi_{r}\left(u_{(i+1)}\right), \text { for } i \in[0, n-4] \\
\Psi_{r}\left(v_{0}\right)+\Psi_{r}\left(v_{i} v_{0}\right)+\Psi_{r}\left(v_{i}\right)+\Psi_{r}\left(v_{i} u_{i}\right)+\Psi_{r}\left(u_{i}\right) \\
+\Psi_{r}\left(u_{i} u_{(i+1)}\right)+\Psi_{r}\left(u_{(i+1)}\right), \text { for } i=[n-3] \\
\Psi_{r}\left(v_{1}\right)+\Psi_{r}\left(v_{i} v_{1}\right)+\Psi_{r}\left(v_{i}\right)+\Psi_{r}\left(v_{i} u_{i}\right)+\Psi_{r}\left(u_{i}\right) \\
+\Psi_{r}\left(u_{i} u_{(i+1)}\right)+\Psi_{r}\left(u_{(i+1)}\right), \text { for } i=[n-2] \\
\Psi_{r}\left(v_{2}\right)+\Psi_{r}\left(v_{i} v_{2}\right)+\Psi_{r}\left(v_{i}\right)+\Psi_{r}\left(v_{i} u_{i}\right)+\Psi_{r}\left(u_{i}\right) \\
+\Psi_{r}\left(u_{i} u_{1}\right)+\Psi_{r}\left(u_{0}\right), \text { for } i=[n-1]
\end{array}\right.
$$

For $i \in[0, n-1]$, under labeling $\psi_{r}$, we find

$$
\begin{aligned}
w\left(P_{4}^{i}\right)= & \Psi_{r}\left(v_{(i+3)}\right)+\Psi_{r}\left(v_{i} v_{(i+3)}\right)+\Psi_{r}\left(v_{i}\right)+\Psi_{r}\left(v_{i} u_{i}\right)+\Psi_{r}\left(u_{i}\right)+\Psi_{r}\left(u_{i} u_{(i+1)}\right)+\Psi_{r}\left(u_{(i+1)}\right) \\
= & (4 n+(i+3)-2)+(i+1)+(5 n+i-2)+(2 n+i-1)+(3 n-i+3)+(2 n+ \\
& i+1)+(3 n-(i+1)+3) \\
= & 19 n+3 i+5
\end{aligned}
$$

Since $w\left(P_{4}^{i+1}\right)-w\left(P_{4}^{i}\right)=3$ and $w\left(P_{4}^{0}\right)=19 n+5$, the generalized Peterzen $\operatorname{GPz}(n, 3) a$ dmits a $(19 n+5,3)-P_{4}$-antimagic decomposition.

Theorem 4. For any integer $n \geq 7$, the graph $G P z(n, 3)$ has a $(13 n+5,4)$ - $P_{4}$-antimagic decomposition.

Proof. Define a total labeling $\Psi_{t}$ on the edges and vertices of the graph $\operatorname{GPz}(n, 3)$ in the following way

$$
\begin{array}{lll}
\Psi_{t}\left(v_{i} v_{(i+3) \bmod n}\right) & = \begin{cases}4 n-i+1 & \text { for } i=0 \\
5 n-i+1 & \text { for } i \in[1, n-1]\end{cases} \\
\Psi_{t}\left(v_{i} u_{i}\right) & = \begin{cases}4 n+i-3 & \text { for } i \in[0,3] \\
3 n+i-3 & \text { for } i \in[4, n-1]\end{cases} \\
\Psi_{t}\left(u_{i} u_{(i+1) \bmod n)}\right) & \begin{array}{ll}
n+2+2 i & \text { for } i \in[0, n-1]
\end{array} \\
\Psi_{t}\left(u_{i}\right) & = \begin{cases}3 n+2 i-1 & \text { for } i=0 \\
n+2 i-1 & \text { for } i \in[1, n-1]\end{cases} \\
\Psi_{t}\left(v_{i}\right) & = \begin{cases}4-i & \text { for } i \in[0,3] \\
n+4-i & \text { for } i \in[4, n-1]\end{cases}
\end{array}
$$

It can be seen that the labeling $\psi_{t}$ is a bijective function from $E(G P z(n, 3)) \cup V(G P z(n, 3))$ to $\{1,2,3,4, \ldots, 3 n\}$ and $\psi_{t}(V(G P z(n, 3)))=\{1,2,3,4, \ldots, n+1\}$. Furthermore, the $P_{4}$-weight under the labeling $\psi_{t}$ are as follows 


$$
w\left(P_{4}^{i}\right)=\left\{\begin{array}{c}
\Psi_{t}\left(v_{(i+3)}\right)+\Psi_{t}\left(v_{i} v_{(i+3)}\right)+\Psi_{t}\left(v_{i}\right)+\Psi_{t}\left(v_{i} u_{i}\right)+\Psi_{t}\left(u_{i}\right) \\
+\Psi_{t}\left(u_{i} u_{(i+1)}\right)+\Psi_{t}\left(u_{(i+1)}\right), \text { for } i \in[0, n-4] \\
\Psi_{t}\left(v_{0}\right)+\Psi_{t}\left(v_{i} v_{0}\right)+\Psi_{t}\left(v_{i}\right)+\Psi_{t}\left(v_{i} u_{i}\right)+\Psi_{t}\left(u_{i}\right) \\
+\Psi_{t}\left(u_{i} u_{(i+1)}\right)+\Psi_{t}\left(u_{(i+1)}\right), \text { for } i=[n-3] \\
\Psi_{t}\left(v_{1}\right)+\Psi_{t}\left(v_{i} v_{1}\right)+\Psi_{t}\left(v_{i}\right)+\Psi_{t}\left(v_{i} u_{i}\right)+\Psi_{t}\left(u_{i}\right) \\
+\Psi_{t}\left(u_{i} u_{(i+1)}\right)+\Psi_{t}\left(u_{(i+1)}\right), \text { for } i=[n-2] \\
\Psi_{t}\left(v_{2}\right)+\Psi_{t}\left(v_{i} v_{2}\right)+\Psi_{t}\left(v_{i}\right)+\Psi_{t}\left(v_{i} u_{i}\right)+\Psi_{t}\left(u_{i}\right) \\
+\Psi_{t}\left(u_{i} u_{1}\right)+\Psi_{t}\left(u_{0}\right), \text { for } i=[n-1]
\end{array}\right.
$$

For $i \in[0, n-1]$, under labeling $\psi_{t}$, we find

$$
\begin{aligned}
w\left(P_{4}^{i}\right)= & \Psi_{t}\left(v_{(i+3)}\right)+\Psi_{t}\left(v_{i} v_{(i+3)}\right)+\Psi_{t}\left(v_{i}\right)+\Psi_{t}\left(v_{i} u_{i}\right)+\Psi_{t}\left(u_{i}\right)+\Psi_{t}\left(u_{i} u_{(i+1)}\right)+\Psi_{t}\left(u_{(i+1)}\right) \\
= & (-(i+3)+4)+(4 n-i+1)+(-i+4)+(4 n+i-3)+(3 n+2 i-1)+(n+ \\
& 2 i+2)+(n+2(i+1)-1) \\
= & 13 n+4 i+5
\end{aligned}
$$

Since $w\left(P_{4}^{i+1}\right)-w\left(P_{4}^{i}\right)=4$ and $w\left(P_{4}^{0}\right)=13 n+4$, the generalized Peterzen $\operatorname{GPz}(n, 3)$ admits a $(13 n+4,4)-P_{4}$-antimagic decomposition.

Theorem 5. For any integer $n \geq 7$, the graph $G P z(n, 3)$ has a $(18 n+6,5)-P_{4}$-antimagic decomposition. Proof. Define a total labeling $\Psi_{y}$ on the edges and vertices of the graph $\operatorname{GPz}(n, 3)$ in the following way

$$
\begin{array}{llcl}
\Psi_{y}\left(v_{i} v_{(i+3) \bmod n}\right) & = & 2 i+1 & \text { for } i \in[0, n-1] \\
\Psi_{y}\left(v_{i} u_{i}\right) & = & \begin{array}{cl}
2 i+2 & \text { for } i \in[0, n-1]
\end{array} \\
\Psi_{y}\left(u_{i} u_{(i+1) \bmod n}\right) & = & \begin{cases}3 n+i-3 & \text { for } i \in[0,3] \\
2 n+i-3 & \text { for } i \in[4, n-1]\end{cases} \\
\Psi_{y}\left(u_{i}\right) & = & \begin{cases}4 n+i & \text { for } i=0 \\
3 n+i & \text { for } i \in[1, n-1]\end{cases} \\
\Psi_{y}\left(v_{i}\right) & = & \begin{cases}4 n-i+4 & \text { for } i \in[0,3] \\
5 n-i+4 & \text { for } i \in[4, n-1]\end{cases}
\end{array}
$$

It can be seen that the labeling $\psi_{y}$ is a bijective function from $E(G P z(n, 3)) \cup V(G P z(n, 3))$ to $\{1,2,3,4, \ldots, 3 n\}$ and $\psi_{y}(V(G P z(n, 3)))=\{1,2,3,4, \ldots, n+1\}$. Furthermore, the $P_{4}$-weight under the labeling $\psi_{y}$ are as follows 


$$
w\left(P_{4}^{i}\right)=\left\{\begin{array}{c}
\Psi_{y}\left(v_{(i+3)}\right)+\Psi_{y}\left(v_{i} v_{(i+3)}\right)+\Psi_{y}\left(v_{i}\right)+\Psi_{y}\left(v_{i} u_{i}\right)+\Psi_{y}\left(u_{i}\right) \\
+\Psi_{y}\left(u_{i} u_{(i+1)}\right)+\Psi_{y}\left(u_{(i+1)}\right), \text { for } i \in[0, n-4] \\
\Psi_{y}\left(v_{0}\right)+\Psi_{y}\left(v_{i} v_{0}\right)+\Psi_{y}\left(v_{i}\right)+\Psi_{y}\left(v_{i} u_{i}\right)+\Psi_{y}\left(u_{i}\right) \\
+\Psi_{y}\left(u_{i} u_{(i+1)}\right)+\Psi_{y}\left(u_{(i+1)}\right), \text { for } i=[n-3] \\
\Psi_{y}\left(v_{1}\right)+\Psi_{y}\left(v_{i} v_{1}\right)+\Psi_{y}\left(v_{i}\right)+\Psi_{y}\left(v_{i} u_{i}\right)+\Psi_{y}\left(u_{i}\right) \\
+\Psi_{y}\left(u_{i} u_{(i+1)}\right)+\Psi_{y}\left(u_{(i+1)}\right), \text { for } i=[n-2] \\
\Psi_{y}\left(v_{2}\right)+\Psi_{y}\left(v_{i} v_{2}\right)+\Psi_{y}\left(v_{i}\right)+\Psi_{y}\left(v_{i} u_{i}\right)+\Psi_{y}\left(u_{i}\right) \\
+\Psi_{y}\left(u_{i} u_{1}\right)+\Psi_{y}\left(u_{0}\right), \text { for } i=[n-1]
\end{array}\right.
$$

For $i \in[0, n-1]$, under labeling $\psi_{y}$, we find

$$
\begin{aligned}
w\left(P_{4}^{i}\right)= & \Psi_{y}\left(v_{(i+3)}\right)+\Psi_{y}\left(v_{i} v_{(i+3)}\right)+\Psi_{y}\left(v_{i}\right)+\Psi_{y}\left(v_{i} u_{i}\right)+\Psi_{y}\left(u_{i}\right)+\Psi_{y}\left(u_{i} u_{(i+1)}\right)+ \\
& f_{y}\left(u_{(i+1)}\right) \\
= & (4 n-(i+3)+4)+(2 i+1)+(4 n-i+4)+(2 i+2)+(4 n+i)+(3 n+i-3)+ \\
= & (3 n+(i+1)) \\
= & 18 n+5 i+6
\end{aligned}
$$

Since $w\left(P_{4}^{i+1}\right)-w\left(P_{4}^{i}\right)=5$ and $w\left(P_{4}^{0}\right)=18 n+6$, the generalized Peterzen $\operatorname{GPz}(n, 3)$ admits a $(18 n+6,5)-P_{4}$-antimagic decomposition.

\section{CONCLUSION}

In this article, we proved the existence of $(\mathfrak{a}, b)$ - $P_{4}$-antimagic decompositions of the generalized Peterzen graph $\operatorname{GPz}(n, 3)$ for (i) every integer $n \geq 7$ and odd positive integers $b \in\{1,3,5\}$; and (ii) every integer $n \geq 7$ and even positive integers $b \in\{2,4\}$.

The open problems related to these results are as follows:

For every integer $6 \geq n$ and positive integers $b$, find $(a, b)$ - $P_{4}$-antimagic decompositions of the generalized Peterzen graph $\operatorname{GPz}(n, 3)$.

\section{Funding}

Supported by the center of research and publication of Syarif Hidayatullah State Islamic University Jakarta.

\section{REFERENCES}

[1] A. Guti'errez and A. Llad'o, , "Magic Coverings," J. Combin. Math. Combin. Comput., vol. 55, pp. 43 - 56, 2005.

[2] N. Inayah, A. Llado and J. Moragas, "Magic and Antimagic H-Decompositions," Discrete Mathematics, vol. 312, pp. 1367-1371, 2012. 
[3] N. Inayah, A. N. M. Salman and R. Simanjuntak, "On (a,d)-H-Antimagic Coverings of Graphs," Journal of Combinatorial Mathematics and Combinatorial Computing, vol. 71, pp. 273-281, 2009.

[4] Hendy, A. N. Mudholifah, K. A. Sugeng and M. Bača, "On H-antimagic decomposition of toroidal grids and triangulations," AKCE International Journal of Graphs and Combinatorics, vol. 17, no. 3, pp. 761 - 770, 2009.

[5] Hendy, "The H-super (anti) magic decompositions of antiprism graphs," AIP Conference Proceedings, vol. 1707, no. 1, 2016.

[6] J. A. Gallian, , "A dinamic survey of graph labelings," Electron. J. Combin, vol. 16, http://www.combinatorics.org/surveys/ds6.pdf, p. \#DS6, 2020.

[7] M. E. Watkins, "A Theorem on Tait Colorings with an Appication to the generalized Peterzen Graph," Journal of Combinatorial Theory, vol. 6, no. 2, pp. 152-164, 1969. 